\title{
Taking a stand for operative vaginal delivery
}

\author{
Christopher Ng MD
}

Cite as: CMAJ 2018 June 18;190:E732-3. doi: 10.1503/cmaj.180668

See related articles at www.cmaj.ca/lookup/doi/10.1503/cmaj.171076 and www.cmaj.ca/lookup/doi/10.1503/cmaj.170371

A gainst a background of growing concern that rates of cesarean delivery in Canada and globally are rising, trial of labour after previous cesarean delivery and operative vaginal delivery (use of forceps, vacuum or other device) have been promoted as safe avenues for prevention of cesarean birth. ${ }^{1}$ However, debate continues about the safety of operative vaginal deliveries, given the possibility that general obstetric skills have declined. We have reached a critical juncture in obstetrics: we can either accept a rapidly diminishing role for operative vaginal delivery or rise to the challenge of optimizing the training and decision-making skills of our providers of obstetric care.

Linked research by Young and colleagues ${ }^{2}$ and Muraca and colleagues $^{3}$ provide Canadian data to fuel this discussion. Both studies are well-designed, large database studies evaluating, respectively, the safety of trial of vaginal delivery after previous cesarean birth and the risk of harms from operative vaginal delivery in women with and without a previous cesarean birth. The studies showed small but significant increases in maternal and neonatal morbidity and mortality with both trial of labour and operative vaginal delivery. These findings compel us to evaluate whether a goal of reducing our cesarean delivery rate could come at too high a cost to our patients. Muraca and colleagues' most recent work, ${ }^{3}$ as well as their previous study looking at trauma rates associated with mid-pelvic operative deliveries, ${ }^{4}$ have shown that the use of operative vaginal delivery is associated with startlingly high rates of severe perineal trauma.

Large-database cohort studies are important as they provide insight into our current performance, open a discussion about that performance and how we might better train future generations of obstetrical providers to improve case selection and performance, and offer evidence that can be shared with patients when making a decision. However, such studies, and even randomized controlled trials, are limited in their ability to capture clinical reasoning and the "art" of medicine.

However, caution would be advisable before acting, as our specialty has a history of prematurely abandoning procedures. The Term Breech Trial ${ }^{5}$ led to a moratorium on vaginal breech deliveries until publications from Europe were able to show relative safety with stricter criteria developed from clinical experience. ${ }^{6}$ Unfortunately, the damage had already been done, with an entire generation of obstetricians lacking sufficient training to provide vaginal breech delivery.

\section{KEY POINTS}

- Emphasis on trial of labour after cesarean and operative vaginal delivery to reduce rates of cesarean birth may warrant evaluation in light of Canadian data.

- Operative vaginal delivery rates and skills are declining and there are fewer opportunities for learners.

- A conscious change in the way we practise and train providers of obstetric care is necessary to preserve this skill for the future.

Inadequate training of new obstetrical providers may be the biggest casualty when evidence emerges of small increases in risk. We need only look to the United States, where operative vaginal delivery rates have fallen substantially, in turn leading to fewer learning opportunities. Data from US national procedure logs from graduating obstetrician-gynecologists showed a decrease in forceps deliveries from 23.8 to 8.4 , between the period of 2002/03 and 2012/13. It is not unsurprising that in 2007 , less than $58 \%$ of graduates of a US residency program felt competent in providing forceps deliveries. ${ }^{8}$

The techniques for operative vaginal deliveries are inherently difficult to teach. In a cesarean delivery, steps are standardized and, for the most part, predictable. Experts have better access to the surgical field and more control of their residents' actions. The force and angle-of-pull in a forceps delivery is difficult to communicate and to assess. Identification of suitable patient candidates for operative vaginal delivery also requires a gestalt that no doubt improves with experience. As fewer operative vaginal deliveries are performed, the comfort of educators dwindles and the need to maintain competence means teaching opportunities diminish.

The standard apprenticeship model may have worked in the past, but with fewer teaching and learning opportunities, this is not sufficient. There must be a conscious effort to maximize the preprocedure training and to allow for deliberate practice and reflection. There have been excellent efforts to create decisionmaking frameworks to distill expertise on managing the second stage of labour and evaluating candidacy for operative vaginal delivery. ${ }^{9,10}$ Promisingly, Gossett and colleagues were able to show a reduction in severe perineal laceration by $22 \%$ after implementing a simulation curriculum in a residency program. ${ }^{11}$ There is room for improvement and reflection for both trainees and staff. 
It is not easy to find the optimal balance of risks and benefits among operative vaginal delivery, trial of labour after cesarean, and cesarean delivery. Unfortunately, that discussion may be cut short as we run the real risk of having the skills for operative vaginal delivery wither as a result of the difficulty in training future providers. Loss of such training for obstetric providers means that we do both patients and providers a disservice by limiting patient choice and therapeutic options. Strong mentorship and teaching, clear intention and firm commitment to improving our own skills and outcomes are required if we do not want to see operative vaginal procedures fade into history, but wish to be able to continue offering options for delivery to obstetric patients.

\section{References}

1. American College of Obstetricians and Gynecologists (College); Society for Maternal-Fetal Medicine; Caughey AB, Cahill AG, Guise JM, et al. Safe prevention of the primary cesarean delivery. Am J Obstet Gynecol 2014;210:179-93.

2. Young CB, Liu S, Muraca GM, et al.; Canadian Perinatal Surveillance System. Mode of delivery after a previous cesarean birth, and associated maternal and neonatal morbidity. CMAJ 2018;190:E556-64.

3. Muraca GM, Lisonkova S, Skoll A, et al. Associations between rates of operative vaginal delivery and frequency of obstetric and birth trauma. CMAJ 2018;190:E734-41.

4. Muraca GM, Sabr Y, Lisonkova S, et al. Perinatal and maternal morbidity and mortality after attempted operative vaginal delivery at midpelvic station. CMAJ 2017;189:E764-72.

5. Hannah ME, Hannah WJ, Hewson SA, et al. Planned caesarean section versus planned vaginal birth for breech presentation at term: a randomised multicentre trial. Term Breech Trial Collaborative Group. Lancet 2000;356: 1375-83.

6. Goffinet F, Carayol M, Foidart JM, et al. Is planned vaginal delivery for breech presentation at term still an option? Results of an observational prospective survey in France and Belgium. Am J Obstet Gynecol 2006;194:1002-11.

7. Gupta N, Dragovic K, Trester R, et al. The changing scenario of obstetrics and gynecology residency training. J Grad Med Educ 2015;7:401-6.

8. Powell J, Gilo N, Foote M, et al. Vacuum and forceps training in residency: experience and self-reported competency. J Perinatol 2007;27:343-6.

9. Hodges R, Simpson A, Gurau D, et al. Learning from experience: development of a cognitive task-list to assess the second stage of labour for operative delivery. J Obstet Gynaecol Can 2015;37:354-61.

10. Bahl R, Murphy DJ, Strachan B. Decision-making in operative vaginal delivery: when to intervene, where to deliver and which instrument to use? Qualitative analysis of expert clinical practice. Eur J Obstet Gynecol Reprod Biol 2013;170:333-40.

11. Gossett DR, Gilchrist-Scott D, Wayne DB, et al. Simulation training for forcepsassisted vaginal delivery and rates of maternal perineal trauma. Obstet Gynecol 2016;128:429-35.

Competing interests: Christopher $\mathrm{Ng}$ reports receiving fees for practising and teaching at Langley Memorial Hospital from the University of British Columbia (UBC) Faculty of Medicine; honoraria from UBC for lectures; and funding from the Fraser Health Physician Engagement Fund to present grand rounds.

This article was solicited and has not been peer reviewed.

Affiliation: Department of Obstetrics \& Gynaecology, University of British Columbia, Vancouver, BC

Correspondence to: Christopher Ng, chrng@alumni.ubc.ca 